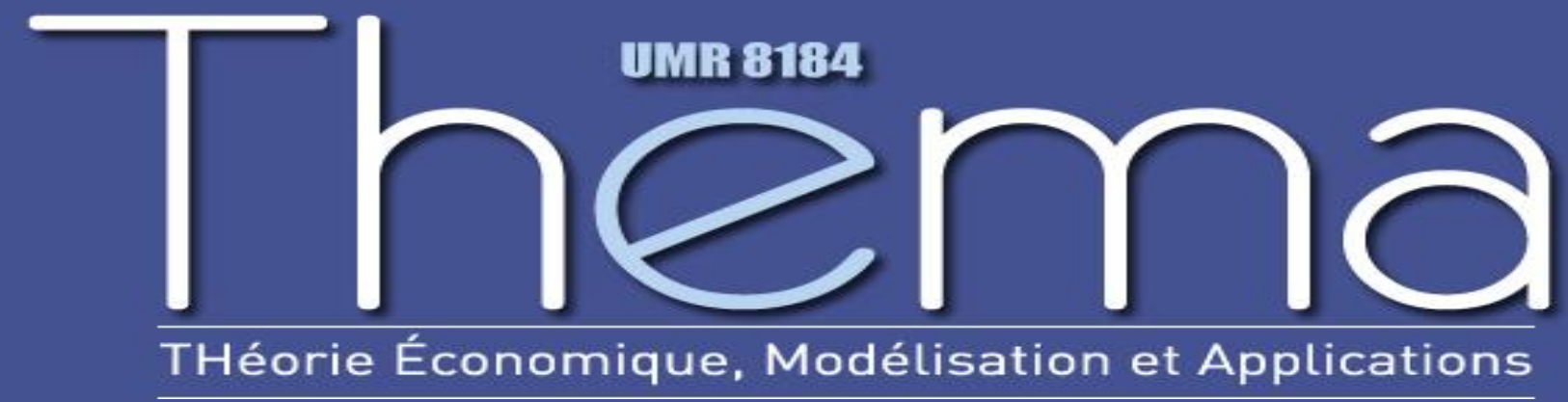

Thema Working Paper $\mathrm{n}^{\circ}$ 2012-35

Université de Cergy Pontoise, France

Hospital Staffing and Local Pay: an Investigation into the Impact of Local variations in the Competitiveness of Nurses Pay on the Staffing of Hospitals in France

Jean-Baptiste Combes

Eric Delattre

Bob Elliot

Diane Skatun

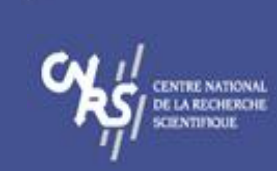

April, 2012 


\title{
Hospital Staffing and Local Pay: an Investigation INTO THE IMPACT OF LOCAL VARIATIONS IN THE Competitiveness of Nurses Pay on the Staffing of HOSPITALS IN FranCE ${ }^{a}$
}

\author{
by Jean-Baptiste Combes ${ }^{b}$, Eric Delattre ${ }^{c}$, Bob Elliott ${ }^{d}$ and Diane Skåtun ${ }^{\mathrm{e}}$
}

April 2012

\begin{abstract}
Research has shown that where nurses' wages are regulated but wages in other sectors are not this results in spatial variations in the competitiveness of nurses pay and that in England these are correlated with spatial differences in nurses' labour supply. In France there is general regulation of wages and public hospitals compete with the private hospital and non hospital sectors for nurses. We construct and employ a unique dataset on nurses pay and the characteristics of hospitals in France. We undertake the first study of the impact of spatial wage differentials on nursing supply to French public hospitals. We show that nurse assistants' labour supply is sensitive to spatial wage differentials, the more competitive their pay the smaller the shortage of nurse assistants, and that registered nurses and nurse assistants labour supply are interdependent, the greater the supply of nurse assistants the greater the supply of registered nurses.

Keywords: Wage regulation, local pay, standardised spatial wage differentials, nursing shortage, nursing labour supply

JEL Codes: I12, I18, J31.

a Our thanks go to the following for their support for this project: to Rennes Métropole for the grant "Allocation Installation Jeunes Chercheurs" and to the University of Aberdeen for financial support; to the Ecole Nationale de la Statistique et de l'Analyse de l'Information, for providing facilities for one of the authors to conduct part of this research; to the Institut National de la Statistique et de l'Analyse Economique for permitting access to and assisting in interpretation of the Déclaration Annuelle des Données Sociales (DADS); to Mehni Benyaala, Martine Delangre, Elodie Kranklader, Alain Esnault for their assistance in accessing and interpreting the DADS and Statistique Annuelle des Etablissements de Santé (SAE); and to Cécile Martin for her comments on this paper at the CES-HESG joint conference in Aix-en-Provence in January 2012. An earlier version of part of this research was presented at Paris, Dauphine and we are grateful to participants for their comments.

b Health Economics Research Unit, University of Aberdeen jeanbaptiste.combes@abdn.ac.uk.

c Ecole Nationale de la Statistique et de l'Analyse de l'Information Eric.DELATTRE@ensai.fr and THEMA (UMR CNRS 8184) eric.delattre@u-cergy.fr.

d Health Economics Research Unit, University of Aberdeen r.elliott@abdn.ac.uk

e Health Economics Research Unit, University of Aberdeen d.skatun@abdn.ac.uk
\end{abstract}




\section{Introduction}

Nurses unions have complained that there are not enough nurses in French hospitals (Depoire, 2011). This nurse shortage is neither new nor confined to France (Com-Ruelle et al., 2000; Simoens et al., 2005; Pourvourville, 2002). Yet according to Baret (2002) there is no measure of nursing shortage in France. The only quantitative evidence for a shortage is a shortfall in recruitment of students to nursing education. The National Observatory on the demography of health professions (Observatoire national de la démographie des professions de santé (ONDPS), 2006) reports widespread regional variations in the shortage of nurses in education suggesting that local conditions play a part in accounting for them ${ }^{1}$. Thus while in 2004 1\% of nurse training places went unfilled in Aquitaine, 22\% went unfilled in Ile de France. While there is much discussion in France about a national shortage of nurses there is none about local variations in nurse shortages and there has been no empirical investigation of this issue. Local variations in nurse shortages would be expected to arise if there are local variations in the competitiveness of nurses pay and local variations in competitiveness can result from wage regulation.

In England centralised regulation of nurses pay means that it is the same across many different local labour markets. In contrast pay in the private sector in England reveals substantial spatial variation because collective bargaining, which was the major mechanism by which pay was regulated in the private sector in England, now plays a minor role (Elliott, 2008). These differences in pay setting result in spatial differences in the competitiveness of nurses pay which can be measured by the 'gaps' between nurses pay and that of their comparators. These gaps have been found to be associated with variations in nursing shortages, as measured by nursing vacancy rates, in hospitals in England: the less competitive nurses pay the higher the vacancy rate (Elliott et al., 2007). In complementary research Propper \& Van Rennen (2010) revealed that spatial variations in the private sector pay were associated with inferior hospital outcomes as measured by higher death rates due to Acute Myocardial Infarction.

In France both nurses pay and the pay of their comparators are regulated. In previous research for France into local wage differentials Combes et al. (2008) suggest that the observed differences in wages between areas of France may be endogenous because workers with higher skills and more productive labour market characteristics locate in higher density, higher skilled and more highly paid regions.

1 In France training places for nurses are funded by the ministry of education. 
The research reported here investigates the spatial patterns of pay that arise under generalised pay regulation and investigates the extent to which these are associated with local variations in the competitiveness of pay of nurses working in public hospitals in France. It explores the association between local variations in the competitiveness of public hospital nurses pay and the supply of nurses to public hospitals in France. It further explores the role that the competitiveness of the pay, and therefore the supply, of co-workers plays in determining nursing labour supply.

In France private for profit and not for profit hospitals operate alongside public hospitals. Thus there would appear to be more direct competitors for nursing staff employed in public hospitals than exist in England. In England hospital services are provided very largely by the NHS and the impact of private sector hospitals on recruitment of nurses to the public sector in England is very small. In this research competitiveness is therefore assessed by measuring the pay of nurses working in public hospitals in France against that of nurses in private sector hospitals and employees at a similar skill level working in the non-hospital private sector.

The research reported in this paper builds on that of Elliott et al. (2007) to investigate whether there are spatial variations in the competitiveness of pay of nurses working in public hospitals in France. It reports the first research into the nature and consequences of local variations in the competitiveness of pay of the nursing workforce in France. Having established the existence of such variations in competitiveness of pay the paper then explores whether they are associated with local variations in the supply of nursing staff to hospitals in France. Recognising that under extended wage regulation wages are unlikely to clear the market the research also explores interdependencies in nursing labour supply which capture an important dimension of local differences in wage characteristics of hospital employment.

The theory of compensating wage differentials provides the theoretical framework underpinning this analysis. It explains why the 'underlying' structure of pay differs between geographical areas where labour markets are unregulated (Smith, 1776; Rosen, 1986). Higher pay in some areas of the country is expected where the cost of living is higher while higher pay is also necessary to compensate for a less pleasant working environment. Empirical research on the topic is not clear cut. Researchers have found that wage differentials, on average, reflect job and individual characteristics (Reilly, 1992; García and Molina, 2002; Pereira and Galego, 2011) but that regional wage differentials only partially reflect differences in amenities and cost of living (Vermeulen and Van Ommeren, 2009; Blackaby and Murphy, 1991, 1995; Shah and Walker, 1983). 
In France pay is set, regulated, centrally through collective bargaining, with $95 \%$ of employees covered by collective bargaining arrangements in 2000 (Traxler and Brandl, 2011). The impact of unions and collective bargaining on the pay structure has been widely studied. The research reveals that where pay is regulated through collective bargaining pay is less likely to vary locally (Rosen, 1986; Traxler and Brandl, 2011; Hayter and Weinberg, 2011; Card et al., 2003; Bassanini and Duval, 2006; Blackaby and Murphy, 1991; Metcalf et al., 2001). Reviewing the link between unions and wage dispersion Hayter \& Weinberg (2011) argue that there is an extended body of literature that confirms that unions tend to compress the wage structure. The coverage of collective bargaining is extensive in France but pay variation, between French regions and localities, may still occur (Meurs and Edon, 2007). Collective bargaining is conducted at several different levels in France. In the private sector, branch (industry) agreements are negotiated nationally and have to be implemented by all firms within a branch (Meurs \& Edon, 2007). However firm agreements can supplement the increases specified in the branch agreement and may be a source of greater local pay variation.

In the public sector local agreements are not possible. If there is no agreement between unions and the employer (the government), the government will award across the board pay increases unilaterally, and there has not been any agreement since 1998 (Meurs \& Edon, 2007).

Grade drift exists in both sectors and is another potential source of local pay variation. Drift may occur in both the public and private sectors though there is no research reporting whether it is more common in one sector than the other to employ this mechanism to increase pay. Meurs \& Edon (2007) found, using the French Labour Force Survey of 2002, that in the private sector (including private for profit hospitals) pay dispersion was greater than in the public sector (all public sector, excluding publicly owned companies) and that the degree of variation (when controlling for individual and firm characteristics) differed across the country. It appears that centralised wage regulation through collective bargaining in France might not eliminate spatial variations in the competitiveness of nurses pay, and that spatial variations in any gap between the pay of nurses in the public and private sectors may exist.

The aim of this paper is two-fold: first to establish the degree of spatial variations in the competitiveness of the pay of nurses in public hospitals in France and second to explore the impact of any variations in competitiveness on spatial variations in the supply of nurses to French hospitals. The paper is in six sections. The following section, Section 2, describes the French hospital sys- 
tem, while Section 3 describes the data which is used in this analysis and Section 4 the construction of Standardised Spatial Wage Differentials. Section 5 presents the models that will be estimated and discusses the results and Section 6 concludes.

\section{French hospital system}

Hospitals in France are divided into three different legal types: public hospitals, private not for profit hospitals and private for profit hospitals. Public hospitals ${ }^{2}$ can be large regional hospitals undertaking education and research and providing acute care, and advanced treatments, or they may be local hospitals which run a smaller acute or maternity ward. Local hospitals depend on large regional hospitals for most of the more advanced care. They also rely on ambulatory care medical doctors to provide some of their services. All public hospitals run an emergency service.

Not for profit hospitals are associations, mutual establishments or foundations, in which any surplus over costs is reinvested into the services provided for patients. For profit hospitals have commercial status and aim to make a profit. Usually of smaller size, no private hospital will be as large as regional public hospitals. Private for profit hospitals tend to specialise in routine procedures. Some private not for profit hospitals participate in the public service.

Publicly funded hospital health-care in France is provided by both public hospitals and those private not for profit hospitals ${ }^{3}$ which participate in the public service ("service public hospitalier") (Code de la Santé Publique, 1993; Adaius et al., 2007). The private hospitals which participate in the public service receive subsidies for equipment. In exchange they have to agree to provide a similar service to that of public hospitals: they have to provide the agreed services at any time of the day and night, they have to either run an emergency ward or be able to redirect patients to a hospital that does (Afrita et al., 2008). Private hospitals also participate in education and research (in small hospitals through taking medical trainees). Those private hospitals that do not participate in the public service receive funding for only the care they perform ${ }^{4}$, they receive no subsidies for equipment.

Two grades of nurses work in French hospitals; registered nurses and nursing assistants. Re-

2 Public hospitals include military hospitals, which report to the ministry of defence. They constitute 9 out of a total of 942 public hospitals and employ $0.68 \%$ and $0.56 \%$ of the total number of registered nurses and nurse assistants respectively.

3 Only 20 out of 910 private-for-profit hospitals participate in the public service while 482 out of 668 private not for profit hospitals participate in the public service.

4 Procedures performed by private hospitals not participating in the public service are, nevertheless, subject to authorisations by the regulatory body (which reports to the ministry of health). 
gistered nurses undergo thirty eight months training ${ }^{5}$ (Com-Ruelle et al., 2000) and are required to qualify and register with Direction Départementale des Affaires Sanitaires et Sociales (DDASS) ${ }^{6}$ in order to practice. Working alongside them are nursing assistants who have 12 months training ${ }^{7}$ (Com-Ruelle et al. 2000). Some registered nurses have an additional qualification, a diploma, and are called specialised registered nurses. Hospitals have an average of $5 \%$ of specialised registered nurses in the total number of registered nurses they employ, and this varies little between hospitals of different status. Nursing staff working in public hospitals generally have the status of civil servants though hospitals can also hire staff under non statutory contracts. Private hospitals hire staff under either open ended contracts (Contrats à durée indéterminée) or fixed term contracts (Contrats à durée déterminée).

\section{Data}

Data on hospitals comes from the "Statistiques Annuelles des Etablissements de Santé" (SAE) which is a dataset available from the French Ministry of Health ${ }^{8}$. This data gives information on all health care premises ("Etablissement de santé") including all public, private not for profit and private for profit hospitals in France. Completion of the SAE is a legal requirement, and thus this data is exhaustive9. Data from the SAE were linked to data from the "Déclarations Annuelles des Données Sociales" (DADS) which is an administrative data set which gives details of the pay and employment of all employees in all firms in France. Each year all companies are required to provide the fiscal and social authorities with the names of all the employees during the past year and to provide information on their sex, age, address, hours worked, position, qualification and the pay they received. The National Institute of Statistics and Economic Studies (INSEE, Institut National de la Statistique et des Études Économiques) check and validate the data.

DADS provides data on the number of nursing staff and other employees in each hospital, providing details of all the positions an individual occupied during the year (in the data an individual

5 Registered nurses receive 38 months training in specialised institutions recognised by the Ministry of Health. Entrance to training is open to anyone who has the baccalauréat and is at least 17 years of age before the end of the year in which the exams are held.

6 Regional authorities (préfet) will grant authorisation to practice following the decision of a regional committee. These regional committees were set up by the Direction Départementale des Affaires Sanitaires et Sociales (DDASS) which, up to 2010, were the public bodies in charge of organisation of health care at the département level.

7 Nurse assistants receive 12 months training in institutes that are recognised by the Ministry of Health. Entrance to training is open to anyone who has completed a secondary education and achieved the brevet des collèges (BEPC) and is at least 17 years of age before the end of the year in which the exams are held.

8 http://www.sae-diffusion.sante.gouv.fr/ accessed the $18^{\text {th }}$ of April 2012.

9 http://www.sante.gouv.fr/statistique-annuelle-des-etablissements-sae.html accessed the $18^{\text {th }}$ of April 2012. 
may be represented by more than one row). Two formats of this data exist, one which is exhaustive and which was used when extracting data for nurses and the other which is a sample of 1 in 12 and which was used in this analysis of the non-nursing comparator group. Data on the pay of individual nurses comes from DADS.

Data from three years are used, 2006 to 2008. The choice of these three years is driven by data availability; only from 2006 can we distinguish highly disaggregated occupational groups in the pay data and therefore only from 2006 onwards can registered nurses and nurse assistants be distinguished from other groups of carers such as social assistants.

Hospitals with no registered nurses or no nurse assistants have been excluded from the data. Those which are not in all the years for which the analysis is undertaken have also been excluded. Overall the final dataset includes 942 public hospitals in each of the three years, this gives a total of 2826 public hospitals. Only hospitals which do not change status over time have been retained in the dataset

Table 1 presents descriptive statistics by the types of hospitals. It shows that public hospitals appear to be larger, for they employ more nurses and nursing assistants. While on average, there are 88 whole time equivalent (WTE) nursing assistants in each hospital, there are 190 WTEs in public hospitals but only 28 WTE nursing assistants in private not for profit and 25 WTEs in private for profit hospitals. Similar variations are observed for registered nurses: on average hospitals have 111 WTE registered nurses, public hospitals have 230 and private hospitals have around 39.

[Insert Table 1 near here]

Public and private sector hospitals also differ in activity. Public hospitals are more likely to have medicine, surgery and obstetric (MSO), psychiatry (PSY) and long stay (LST) wards than either of the two private hospital types. The proportion of hospitals with MSO, PSY and LST wards is $72 \%$, $22 \%$ and $85 \%$ respectively in the public sector while the shares are $29 \%, 7 \%$ and $67 \%$ respectively for private not for profit hospitals and 54\%, 14\% and 33\% respectively for private for profit hospitals.

\subsection{Pay}

In the following analysis we shall use data on the net wage, which is the wage after deductions of 
payments for social benefits (pensions, health insurance, unemployment benefits). Deductions differ between sectors, for example public sector workers do not contribute to unemployment insurance (Bartoli and Bras, 2007) while this is deducted from private sector pay. Thus gross pay is not comparable across sectors. We follow Meurs \& Edon (2007) who used "net pay"10, when they investigated the impact of pay in the private sector on pay in the public sector.

Two main collective agreements set the pay of nursing staff in the private sector. The FEHAP ${ }^{11}$ covers $70 \%$ of staff in private not for profit hospitals and the $\mathrm{FHP}^{12}$ covers $90 \%$ of staff in private for profit hospitals ${ }^{13}$. There are advantages to working in public hospitals. The statutory contracts in public hospitals are life time contracts. A household with one member having such a contract will have less difficulty obtaining a mortgage compared to a household with the same income without such a contract.

Average pay as reported in DADS is shown in Table 2. Both gross and net pay are reported and Table 2 shows this differs by hospital type. Nursing assistants and registered nurses in public hospitals earn more on average than their private sector counterparts: net pay of $11.33 €$ per hour and $14.18 €$ per hour, respectively, compared to net pay of $10.02 €$ per hour and $13.71 €$ per hour in private not-for-profit hospitals and 9.53€ per hour and $13.35 €$ per hour in private for profit hospitals. Gross pay reveals a different picture, with private not for profit paying the highest gross wages. Our concern is with the attractiveness to nurses of pay in different types of hospitals and localities and thus we focus on net pay.

[Insert Table 2 near here]

\subsection{Geography}

Hospitals in France can be assigned to the following geographical areas: communes, départements and régions. There are 36000 communes but only 22 régions in France. Most communes cover a small geographical area and therefore do not constitute the labour markets in which nurses are recruited. Equally regions are too large and encompass several labour markets. Travel To Work Areas (TTWAs) have been mapped for France ${ }^{14}$, however as with other countries these describe

10 As defined in France, gross pay minus social contributions but without deducting income tax.

11 Federation of not for profit hospital and private assistance premises (Fédération des établissements hospitaliers et d'assistance privés à but non lucratif).

12 Private federation of hospitals (Fédération hospitalière privée).

13 All hospitals are covered by a collective agreement.

14 There are 341 "zones d'emploi" in France. 
the average travel to work area across all employees and they are not identified for specific occupations though we know TTWAs differ by occupation. TTWAs for nurses in France would have identified the appropriate geography, but they are not available. In the absence of such a mapping the département is chosen; there are 96 départements in metropolitan France. Départements have the advantage that they have not changed over the years. The characteristics of all hospitals of each type in each département are used to compute the average characteristics by type of hospital in each département. The average staffing level for nurse assistants and registered nurses levels, the average number of MSO, PSY and LST wards, the average number of private hospitals participating in the public service and the average size, and equipment and occupancy components are computed for each département,

\section{Standardised Spatial Wage Differentials}

The average pay of nurses working in the different départements in France will be affected by the characteristics and working patterns of the nurses working in the hospitals in each département. The proportions working full time and the gender and age composition of the nursing workforce will differ between hospitals and as a result average pay levels will differ between hospitals and between départments. Pay in the private non hospital sector will also vary spatially because the occupational and industrial composition of the workforce will differ spatially. To distinguish the underlying spatial structure of pay we therefore control for differences in the composition of the workforces and working patterns in each département.

Pay is standardised by calculating Standardised Spatial Wage Differentials (SSWDs). SSWDs are estimated from a wage equation and represent the parameters on the regional dummies (equation 1) where the equation includes controls for the above compositional and working pattern effects. SSWDs are estimated separately for two groups of staff, nurse assistants and registered nurses in each of the three hospital types: public, private not for profit, private for profit hospitals. SSWDs are also estimated for a further comparator group of employees working in the private for profit non hospital sector. In this latter case the comparator group is defined as staff belonging to the same occupational code (Professions et Catégories Socioprofessionnelles) as nursing assistants and registered nurses ${ }^{15}$. The value of the SSWD in any département reveals by how much standardised pay differs from pay in the reference départment, the reference area). SSWDs are estimated as follows:

15 For those employees, the sample is $1: 12^{\text {th }}$ as described earlier. 
Equation 1: Equations for SSWDs estimation

$$
\begin{aligned}
& l h_{i k j}=\alpha+x_{i j} * \beta+\gamma_{j} * \mu_{k}+\varepsilon_{i k j}, j=\text { Nurses Public sector PU } \\
& l h_{i k j}=\alpha+x_{i j} * \beta+\gamma_{j} * \mu_{k}+\varepsilon_{i k j}, j=\text { Nurses Private not for profit PNP } \\
& l h_{i k j}=\alpha+x_{i j} * \beta+\gamma_{j} * \mu_{k}+\varepsilon_{i k j}, j=\text { Nurses Private for profit PP } \\
& l h_{i k j}=\alpha+x_{i j} * \beta+\gamma_{j} * \mu_{k}+\varepsilon_{i k j}, j=\text { Comparator Private for profit PPC }
\end{aligned}
$$

Where $l h_{i k j}$ is the log of hourly earnings of individual $i$ who works in $j$ sector of the economy in area $k$. The vector $x$ contains all the control variables (age, age-square, gender and year dummies, and for the private for profit non-hospital sector, industry and occupational dummies), $\varepsilon_{i k j}$ are the individual-specific error terms and $\mu_{k}$ are the area-specific effects and $\gamma_{j}$ their associated vector of parameters. The area-specific effects represent the SSWDs and are estimated by including a dummy variable for each area.

The competitiveness of nursing pay is distinguished by computing the gap between the standardised spatial pay of two groups being compared. Three pay gaps are distinguished as follows:

- the differences between the SSWDs of nurses (nurse assistants or registered nurses) in public hospitals and the SSWDs of a comparator group working in the private non-hospital sector;

- the differences between the SSWDs of nurses (nurse assistants or registered nurses) in public hospitals and the SSWDs of nurses (nurse assistants or registered nurses) in hospitals in the not for profit private sector;

- the differences between the SSWDs of nurses (nurse assistants or registered nurses) in public hospitals and the SSWDs of nurses (nurse assistants or registered nurses) in hospitals in the for profit private sector.

The gaps are calculated as differences between the two SSWDs estimated on the relevant samples in the same département (Equation 2). The gap will be larger the greater the difference between the two SSWDs.

\section{Equation 2: Definition of gaps}

gap Nurses Public vs. Nurses Private not for profit $=$ PUSSWD - PNPSSWD

gap Nurses Public vs. Nurses Private for profit $=$ PUSSWD - PPSSWD

gap Nurses Public vs. Private for profit $=$ PUSSWD - PPCSSWD

Where PUSSWD stands for the SSWD vector for nurses working in public sector hospitals, PNP 
stands for nurses working in the private not for profit hospitals, PP stands for nurses working in the private for profit hospitals and PPC stands for the comparator group of employees working outside the hospital sector in firms in the private for profit sector.

Table 3 provides evidence that the competitiveness of nursing assistants and registered nurses pay varies across the départments of France. The SSWD gaps are revealed to vary spatially as evidenced by the range and standard deviations reported in Table 3. For nursing assistants the spatial variation in competitiveness is largest, as evidenced by the standard deviation and range, when their pay is compared to nursing assistants in private not-for-profit hospitals (PNPSSWD). For registered nurses the spatial variation in competitiveness is largest when their pay is compared to registered nurses working in both private not-for-profit hospitals (PNPSSWD) and private for profit hospitals (PPSSWD). Even though pay is regulated in the public and private hospital sectors as well as in the private-not-for-profit sector there are sizeable spatial variations in competitiveness. The next stage of the analysis is to explore the implications of these.

[Insert Table 3 near here]

\section{Supply of nursing staff}

The next stage of the analysis explores whether the spatial variations in the competitiveness of nursing pay reported above are associated with variations in the supply of nursing staff to French hospitals. One measure of hospital nursing staff shortage is hospital vacancy rates for nursing staff, nurse turnover might be another. However there are no data on nursing vacancies, or nursing staff turn-over by small geographical area in France, only the numbers of nursing staff employed in each hospital are available. The relationship between nursing vacancies and the number of nursing staff employed is as follows:

Nursing Vacancies $=$ Desired Nursing Staff Numbers - Actual Nursing Staff Numbers

Thus if it were possible to construct a measure of desired nursing staff numbers the actual number of nursing staff employed could then be deducted to give the number of vacancies and from that a vacancy rate computed. In some countries this would be possible; there are mandated nurse/patient ratios such as exist in California (USA) and Victoria (Australia) (Cook et al., 2012; Gerdtz and Nelson, 2007). In countries with mandated nurse/patient ratio summing the number of patients and multiplying by the mandated ratio would result in a measure of desired nursing 
staff numbers. There is no such mandated ratio in France.

The first stage of the analysis therefore distinguishes the difference between desired and actual levels of nursing staff; the actual number of nursing staff employed is adjusted by a factor reflecting the drivers of the desired level of staffing. These factors are the size and activity mix of the hospitals and the bed occupancy rates. The analysis then explores whether the difference between the desired and actual number of nursing staff employed in public hospitals is sensitive to the competitiveness of the pay of nursing staff in public hospitals.

The data set contains six variables which are associated with hospital size; two record the number of beds devoted to two different types of care and the remaining four the number of places the hospital assigns to other activities. They are the number of beds for complete care ${ }^{16}$ and weekly stays at hospitals ${ }^{17}$ (number of beds on a daily basis for the total year) and the number of places for night care ${ }^{18,}$ ambulatory surgery ${ }^{19}$, day $\operatorname{care}^{20}$ and at home care ${ }^{21}$. The data set also identifies the range of technologies employed in each hospital, these and the ward descriptors detailed above (medicine, surgery and obstetric (MSO), psychiatry (PSY) and long stay (LST) wards) are used to control for differences in activity. Finally occupancy rates are also employed to capture the intensity of activity.

One approach would be to include the measures of hospital size, activity mix and occupancy rates as control variables on the right hand size of the estimating equation. However we have a large number of indicators of each of these dimensions while there are a relatively small number of observations on public hospitals, 942. Including all the measures as independent variables would substantially reduce available degrees of freedom in the estimation.

Principal Component Analysis (PCA) is employed to reduce the number of variables employed in the linear regression analysis. PCA identifies linear combinations (components) that maximise the covariance within the set of variables. It aims to identify those components that are orthogonal to (have a null correlation with) the previous components and having done so each subsequent component therefore captures less variance than the previous one. In consequence a smaller number of components than were initially identified will capture most of the covariance

16 Complete care is major treatments that involve a long admission period.

17 Weekly stays are patients who remain in hospital for less than 5 days.

18 Night care is for patients admitted to stay overnight but who have a daily activity outside the hospital.

19 Ambulatory surgery is small surgery that does not require an overnight stay.

20 Day care is patients who are admitted in the morning and leave the same day.

21 At home care is for people in terminal phases of illness that require hospital admission. 
in the variables (Everitt and Dunn, 2001; 49) ${ }^{22}$. The first two components of the PCA extracted most of the information contained in the six variables described above. The number of nursing staff employed in each hospital was then transformed by a dividing through by the first principal component rescaled to 1-100.

Table 4 presents descriptive statistics for the adjusted staffing levels of registered nurses and nursing assistants. It describes the nursing staff levels where these have been adjusted to account for differences in hospital size. The table reports the average number of staff adjusted for size. Thus adjusting for size public hospitals employ on average 66.32 nurse assistants and 65.48 registered nurses. Clearly the adjusted staffing levels for nursing assistants and registered nurses are very similar in public hospitals, they are however higher for registered nurses than for nursing assistants in both types of private hospitals. There are also substantial differences between hospitals in the same sector as revealed by the Standard deviations and the values at the 90th and 10th deciles.

[Insert Table 4 near here]

PCA was also used to construct a second control variable for inclusion on the right hand side of estimating equations. This second control variable sought to control for those differences in activity resulting from the technology available in the hospital. The data set identified the following types of technology employed in the hospitals. The number of scanners, MRI (Magnetic Resonance Imaging), gamma cameras, Positron emission tomography, lithotriptor, diagnostic sonography (ultrasonography), number of non digital radiography rooms, number of digital radiography rooms, number of vascular radiography rooms, number of electrophysiology rooms, number of coronary catheterization rooms and number of rooms for functional explorations. Technology has been found in some studies to be skill intensive (Pope and Menke, 1990; Acemoglu and Finkelstein, 2008): the higher the technology the higher the requirement for skilled nurses. The first three components of a PCA run on the above variables extracted most of the information of those variables.

A final control was constructed to capture variations in occupancy rates. Occupancy is calculated by dividing the level of activity, the number of days devoted to care of the types outlined above, by the number of beds assigned to the same types of care ${ }^{23}$. The first three components of a PCA

22 Each variable has been centred and scaled to 0 so that all variables have the same weight.

23 The number of days of complete care and weekly care divided by the number of day-beds assigned to complete 
run on those variables extracted most of the information in these variables.

Appendix Table A reports the variation in each of the components resulting from the PCA by type of hospital. A larger mean value for public hospitals indicates that hospitals scored high on the component and that therefore they have large values on the corresponding original variables that are associated with the component. Public hospitals are always larger on the two components of size, private not for profit are larger than private for profit on the second component but not on the first. Public hospitals have, on average, larger values on the first and third components of equipment while they have on average the smallest values on the second component. Private not for profit hospitals have larger values on all components of equipment compared to private for profit. Public hospitals have larger values on the first component of the occupancy rates, and smaller ones on the second one. Private for profit hospitals have larger values on the second and third components of the occupancy rates

The supply of nursing staff is measured by actual number of nursing staff employed in public hospitals in France where this has been adjusted as detailed above. The estimating equation is:

Equation 3: Supply of staff models

$$
\frac{\operatorname{Staff} W T E_{j k}^{N_{1}}}{\operatorname{Size}_{j k}^{N_{1}}}=\alpha+\beta_{1} * \operatorname{Gap}_{k}^{N_{1}}+\beta_{3}^{C} * X_{j k}^{C}+\varepsilon_{j k}
$$

Where $\frac{\operatorname{Staff} W T E_{j k}^{N_{1}}}{\operatorname{Size}_{j k}^{N_{1}}}$ is the standardised number of nursing staff (either nursing assistants or registered nurses) employed in hospital $j$ in département $k$. Size1 is the first component of the PCA performed on the beds/places variables. $\alpha$ is the intercept of the model, $\beta_{1}$ is the parameter which measures the competitiveness of the pay of the nursing staff group for whom the equation is estimated. $X_{j k}^{C}$ is the vector of activity variables for hospital $j$ in département $k$ and $\varepsilon_{j}$ is the error term.

The standardised number of nursing staff provides an indicator of the extent to which actual nursing staff numbers are equal to desired nursing staff numbers. The higher the standardised staff number the closer are actual to desired nursing staff numbers.

Above it was shown that the gap has been defined as the difference between the SSWD for reand weekly care. The number of patients that are admitted for ambulatory surgery, day care, night care and at home care divided by the number of beds available for ambulatory surgery, day care, night care and at home care. 
gistered nurses working in public hospitals and the comparator group. It follows that the greater the gap the more competitive is public hospital nursing staff pay and thus, the higher the standardised (after controlling for the other determinants of staff levels) staff number is expected to be. Thus a positive sign is expected: the more competitive is registered nurses (nursing assistants) pay the closer the actual number of registered nursing (nursing assistant) staff will be to desired number of registered nursing (nursing assistant) staff.

Three different gaps, measure the competitiveness of nurses pay, their construction has been described in Section 3 above.

The data set contains repeated observations on individual hospitals; each hospital has observations for three years. With repeated observations on hospitals, the assumption of homoscedasticity of observations is no longer sustainable. Consequently, in the following regression analysis the variance-covariance matrix is adjusted to take into account repeated observations. The modified variance-covariance will give cluster-robust standard errors (Arai, 2011).

The results are reported in Table 5 below. The estimating equations control for spatial differences in hospital activity, through inclusion of three dummies capturing: broad levels of activity, where these have been defined as medicine, surgery and obstetric (MSO), long stay (LST), and psychiatry (PSY); the technology the hospital employs, through the inclusion of the variables constructed using PCA, and; hospital occupancy rates through inclusion of the variables which were again constructed through PCA as described above.

[Insert Table 5 near here]

Two measures of the competitiveness of the pay of nursing assistants working in public hospitals are significant. First the measure of competitiveness against that of nursing assistants working in private for profit hospitals and second the measure of competitiveness against that of comparably skilled employees working in the private sector outside hospitals, the latter is by far the most significant. The same model was also run for registered nurses but the results which are reported in Table 6 below are not significant.

[Insert Table 6 near here]

Nursing assistants have less training, less human capital than registered nurses, and the human 
capital they have is likely to be more transferable, less specific to nursing. Accordingly their labour supply to public hospitals would be expected to be more sensitive to pay in other jobs than is that of registered nurses. It is shown to be sensitive to the pay of nursing assistants in private for profit hospitals and pay in jobs outside the hospital sector. Both these two sectors contain forprofit firms which would be expected to use what flexibilities exist through wage drift and local bargaining to adjust wages to achieve the desired labour supply.

Nor is it surprising that the supply of registered nurses to public hospitals is not less sensitive to pay in other hospital sectors or in jobs outside nursing. There are two reasons for this. First in public hospitals they are most usually employed as civil servants and as a result enjoy life-time contracts. Second they have much higher levels of human capital and a large part of this will be specific to the hospital sector. The higher the level of specific human capital the lower will be the return to prior training of registered nurses if they work outside the hospital sector (Becker, 1964; Elliott, 1991). For registered nurses the effective choices are likely between working in public hospitals or working in private hospitals and the pecuniary advantages would appear to strongly favour the former.

The results for registered nurses provide empirical support for an important general point. Where there is generalised pay regulation pay will not adjust to clear the labour market and as a result, labour supply will be more sensitive to other, non-pay, features of jobs. The theory of compensating differentials makes clear that it is the whole of the advantages and disadvantages of jobs that tend to equality, and if pay is regulated adjustment toward equilibrium will take place through changes in other aspects of jobs. Other, non-pay, characteristics of the jobs nurses do in public and private hospitals or in other jobs outside the hospital sector are likely to become more important in balancing supply and demand and therefore in explaining the supply of nursing staff to public hospitals in France. Because pay is regulated in all sectors in France we would expect the supply of nursing labour to public hospitals to be less sensitive to pay in France than it is in England where private sector pay is unregulated.

The analysis underpinning Tables 5 and 6 has revealed that staffing levels of both nursing assistants and registered nurses are significantly associated with a range of variables that capture the different activities within hospitals, the different technologies they employ and the occupancy rates, each one of these variables provides an indicator of some of the non pay aspects of nursing jobs that are likely of importance to nurses. All else equal the lower the occupancy rate the less 
arduous the job of a nurse, while technology and activity mix may be drivers of the challenge and interest of jobs. However none of these can unambiguously be interpreted as capturing the nonpecuniary advantages and disadvantages of nursing jobs because they are clearly associated with determinants of staffing levels. Accordingly we explore another more distinguishable dimension of nursing jobs that may act as an adjustment mechanism where pay is unable to clear the market; this is the presence of co-workers.

Where there are insufficient numbers of co-workers, the intensity and arduousness of work is likely to increase. Nursing assistants work with registered nurses and if hospitals are unable to attract sufficient numbers of registered nurses additional work has to be done by the nursing assistants, and vice versa. Accordingly at the next stage equation 3 is augmented to include a measure of the competitiveness of the pay of the other nursing group (registered nurses in the case of nursing assistants and vice versa). The estimating equation is below:

Equation 4: Supply of staff models

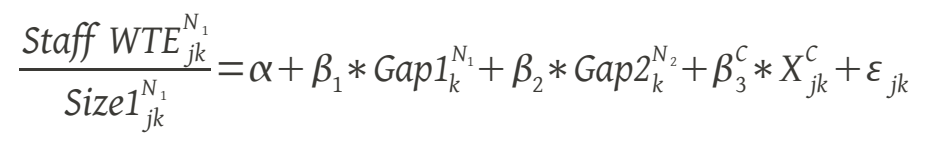

Where $\operatorname{Gap} 2{ }_{k}^{N_{2}}$ measures the competitiveness of the pay of the other nursing staff group. The results are reported in Tables 7 and 8 below. We again expect a positive sign: the more competitive is nursing assistants pay (and therefore the closer the actual number of nursing assistants to the desired number of nursing assistants) the more attractive are jobs in the same hospital to registered nurses and therefore the closer the actual number of registered nurses to the desired number of registered nurses (and vice versa).

[Insert Tables 7 and 8 near here]

In the estimation for nurse assistants none of the registered nurse gaps are significant, it does not appear to matter to nursing assistants whether there are sufficient numbers of registered nurses working in the same hospital. This is as might be expected for there is little scope for the less well trained nursing assistants to be asked to undertake the tasks that would have been performed by the more highly trained registered nurses, and so the absence of registered nurses does not mean (much) extra work for them. However it will be very different for registered nurses. There will be few if any skill or legal barriers to registered nurses undertaking some of the tasks that might otherwise be done by nurse assistants. The results reported in Table 8 show that the supply of re- 
gistered nurses in public hospitals is sensitive to the competitiveness of nursing assistants pay when this is judged against the pay of similar occupations outside the hospital sector. The appeal to registered nurses of working in public hospitals is less if public hospitals do not have the desired number of nursing assistants.

\section{Discussion and conclusions}

The research reported above has shown that even in an economy in which wages in both the public and private sectors are regulated to be the same across many different geographic labour markets there are substantial local variations in the competitiveness of nurses pay. It has been shown that these variations in competitiveness matter; they give rise to local variations in the supply of nursing staff to public hospitals.

In France private hospitals employ nurses and supply a much larger share of hospital services than they do, for example, in the UK. However it is only the wage competition of private for profit hospitals that effects the supply of nursing assistants to public hospitals, any wage competition from not for profit hospitals has no effect. Moreover the supply of nursing assistants to public hospitals is significantly affected by wage competition from the non hospital sector. The analysis shows that the less competitive is nursing assistants pay in public hospitals to that in the non hospital for profit sector the lower is the supply of nursing assistants to public hospitals. Nursing assistants labour supply is sensitive to pay in jobs of comparable skill level in the non hospital private sector.

In contrast the competitiveness of their pay does not affect the supply of registered nurses to public hospitals. Regardless of whether competitiveness is judged against pay in other hospitals or pay in the private sector this has no significant effect on registered nurses labour supply. However that does not mean registered nurses are unconcerned about pay competitiveness: the research reveals they are. What matters to registered nurses is the competitiveness of nursing assistants pay for this determines the supply of nursing assistants. If there are too few nursing assistants registered nurses will be asked to undertake some of the work of nursing assistants. Registered nurses are less attracted to work in public hospitals in localities in which the wages of nursing assistants are uncompetitive and therefore staffing levels of nursing assistants are too low.

A general conclusion emerges; in economies in which wages in general are mandated to be the 
same across different local labour markets and in which the scope for local wage adjustment is therefore restricted, as in France, though there will still be spatial variations in the competitiveness of the wages of different occupational groups there are unlikely to be sufficient to clear the labour market. In this case other non-wage aspects of employment, working conditions, will aslo be important adjustment mechanisms. The research has shown that in the public hospital sector registered nurses are concerned about the supply of co-workers, nursing assistants, and that in localities in which there are too few nursing assistants this will have an adverse effect on registered nursing labour supply.

\section{References}

Acemoglu D, Finkelstein A. Input and Technology Choices in Regulated Industries: Evidence from the Health Care Sector. Journal of Political Economy 2008; 116; 837-880.

Adaius G, Arnault S, Fénina A, Fizzala A, Haury B, Le Rhun B, Leroux I, et al. 2007. Les établissements de santé: Un panorama pour l'année 2005. 07.0112. Direction de la recherche, des études, de l'évaluation et des statistiques (DREES): Paris; 2007.

Afrita A, Arnault S, Aude J, Clerc M-E, Collet M, Com-Ruelle L, Cordier M, et al. 2008. Les établissements de santé: Un panorama pour l'année 2006. 09014. Direction de la recherche, des études, de l'évaluation et des statistiques (DREES): Paris; 2008.

Arai M. Cluster-robust standard errors using R. Stockholm University, Stockholm, Sweden; January 31, 2011.

Baret C. Hôpital: le temps de travail sous tension. Une comparaison Belgique, Italie, France, Grande-Bretagne, PaysBas et Suède. Sciences Sociales Et Santé 2002; 20; 75-107.

Bartoli F, Bras P-L. Tarification à l'activité et écarts de coûts du travail entre les établissements publics et PSPH. FRANCE. Inspection générale des affaires sociales. La Documentation française; 2007.

Bassanini A, Duval R. 2006. Employment Patterns in OECD Countries: Reassessing the Role of Policies and Institutions. OECD Economics Department Working Papers 486. OECD Publishing; June 2006. Available at: http://ideas.repec.org/p/oec/ecoaaa/486-en.html.

Becker GS. Human Capital. Columbia University Press for the National Bureau of Economic Research: New York; 1964.

Blackaby DH, Murphy PD. Industry Characteristics and Inter-Regional Wage Differences. Scottish Journal of Political Economy 1991; 38; 142-161.

- - Earnings, Unemployment and Britain's North-South Divide: Real or Imaginary? Oxford Bulletin of Economics and Statistics 1995; 57; 487-512.

Card D, Lemieux T, Craig W. 2003. Unions and the wage structure. In: Addison JT, Schnabel C (Ed). International Handbook of Trade Unions. Edward Elgar Publishing Limited: Cheltenham, UK and Northamption, MA, USA; 2003. p. 246.

Code de la Santé Publique. Dispositions propres aux établissements de santé privés qui assurent l'exécution du service public hospitalier ou sont associés à son fonctionnement. Article L715. Code De La Santé Publique. 1993. 
Combes P-P, Duranton G, Gobillon L. Spatial wage disparities: Sorting matters! Journal of Urban Economics 2008; 63; 723-742.

Com-Ruelle L, Midy F, Ulmann P. 2000. La profession infirmière en mutation. Eléments de réflexion à partir d'exemples européens. 33. Questions d'Economie de la Santé. Centre de Recherche, d'étude et de Documentation en Economie de la Santé (Credes): Paris; 2000. Available at: www.irdes.fr/Publications/Qes/Qes33.pdf.

Cook A, Gaynor M, Stephens Jr M, Taylor L. The effect of a hospital nurse staffing mandate on patient health outcomes: Evidence from California's minimum staffing regulation. Journal of Health Economics 2012; 31; 340-348.

Depoire N. Hôpitaux: “On est devant une pénurie d'infirmières et d'infirmiers"Europe 1. June $10,2011$. http://www.europe1.fr/France/Hopitaux-On-est-devant-une-penurie-E1-580803/.

Elliott RF. Labour Economics: A Comparative Text. McGraw-Hill Publishing Co.: London; 1991.

-_- 2008. Local Pay. In: Corby S, Palmer S, Lindop E (Ed). Rethinking Reward, vol. Chapter 5. Palgrave Macmillan; October 7, 2008.

Elliott RF, Ma A, Scott A, Bell D, Roberts E. Geographically differentiated pay in the labour market for nurses. Journal of Health Economics 2007; 26; 190-212.

Elliott RF, Ma A, Sutton M, Skatun D, Rice N, Morris S, Mcconnachie A. The role of the staff MFF in distributing NHS funding: Taking account of differences in local labour market conditions. Health Economics 2010; 19; 532-548.

Everitt BS, Dunn G. Applied Multivariate Data Analysis. 2nd ed. Wiley; 2001.

García I, Molina JA. Inter-regional wage differentials in Spain. Applied Economics Letters 2002; 9; $209-215$.

Gerdtz MF, Nelson S. 5-20: a model of minimum nurse-to-patient ratios in Victoria, Australia. Journal of Nursing Management 2007; 15; 64-71.

Hayter S, Weinberg B. 2011. Mind the Gap: collective bargaining and wage inequality. In: Hayter S (Ed). The Role of Collective Bargaining in the Global Economy. Edward Elgar: Cheltenham, UK and Northamption, MA, USA; 2011.

Metcalf D, Hansen K, Charlwood A. Unions and the Sword of Justice: Unions and Pay Systems, Pay Inequality, Pay Discrimination and Low Pay. National Institute Economic Review 2001; 176; 61-75.

Meurs D, Edon C. France: A Limited Effect of Regions on Public Wage Differentials? The Manchester School 2007; 75; 479-500.

Observatoire national de la démographie des professions de santé (ONDPS). Rapport annuel de l'Observatoire national de la démographie des professions de santé-2005. La documentation Française; 2006.

Pereira J, Galego A. Regional wage differentials in Portugal: Static and dynamic approaches. Papers in Regional Science 2011; 90; 529-548.

Pope GC, Menke T. Hospital Labor Markets in the 1980s. Health Affairs 1990; 9; 127.

Pourvourville G de. Rythmes et irréversibilité dans les transformations du système de santé en France. Santé, Société Et Solidarité 2002; $1 ; 45-51$.

Propper C, Van Reenen J. Can Pay Regulation Kill? Panel Data Evidence on the Effect of Labor Markets on Hospital Performance. Journal of Political Economy 2010; 118; 222-273. 
Reilly B. An Analysis of Local Labour Market Wage Differentials. Regional Studies 1992; 26; 257-264.

Rosen S. 1986. Chapter 12 The theory of equalizing differences. In: Ashenfelter OC, Layard R (Ed), vol. Volume 1. Handbook of Labor Economics. Elsevier; 1986. pp. 641-692.

Shah A, Walker M. The distribution of regional earnings in the UK. Applied Economics 1983; 15; 507-520.

Simoens S, Villeneuve M, Hurst J. Tackling Nurse Shortages in OECD Countries: 2005. http://new.sourceoecd.org/vl=567727/cl=20/nw=1/rpsv/workingpapers/18152015/wp_5lgsjhvj747g.htm.

Smith A. An Inquiry into the Nature and Causes of the Wealth of the Nations. W. Strahan and T. Cadell: London; 1776.

Traxler F, Brandl B. 2011. The economic impact of collective bargaining coverage. In: Hayter S (Ed). The Role of Collective Bargaining in the Global Economy. Edward Elgar: Cheltenham, UK and Northamption, MA, USA; 2011.

Vermeulen W, Van Ommeren J. Compensation of regional unemployment in housing markets. Economica 2009; 76; 71-88. 
Table 1: Numbers of Nursing Staff by Hospital Type hospitals

\begin{tabular}{|c|c|c|c|c|c|c|}
\hline Variables & Hospitals & Mean & SD & P50 & P10 & P90 \\
\hline \multirow[t]{4}{*}{ Nurse Assistants (WTE) } & Total & 88.10 & 448.87 & 30.50 & 6.00 & 171.48 \\
\hline & Public & 190.58 & 721.53 & 79.40 & 27.40 & 379.05 \\
\hline & Private not for profit & 28.47 & 38.61 & 18.00 & 3.65 & 64.21 \\
\hline & Private for profit & 25.79 & 26.46 & 16.80 & 4.30 & 58.28 \\
\hline \multirow[t]{4}{*}{ Registered nurses (WTE) } & Total & 110.86 & 473.44 & 24.08 & 6.50 & 255.74 \\
\hline & Public & 230.81 & 756.07 & 59.70 & 10.25 & 523.16 \\
\hline & Private not for profit & 39.73 & 68.27 & 13.17 & 4.00 & 110.10 \\
\hline & Private for profit & 38.90 & 43.51 & 22.87 & 7.00 & 97.77 \\
\hline \multirow{4}{*}{$\begin{array}{l}\text { Medicine, Surgery and } \\
\text { Obstetric }\end{array}$} & Total & 0.54 & 0.50 & 1.00 & 0.00 & 1.00 \\
\hline & Public & 0.72 & 0.45 & 1.00 & 0.00 & 1.00 \\
\hline & Private not for profit & 0.29 & 0.45 & 0.00 & 0.00 & 1.00 \\
\hline & Private for profit & 0.54 & 0.50 & 1.00 & 0.00 & 1.00 \\
\hline \multirow[t]{4}{*}{ Psychiatric wards } & Total & 0.15 & 0.36 & 0.00 & 0.00 & 1.00 \\
\hline & Public & 0.22 & 0.41 & 0.00 & 0.00 & 1.00 \\
\hline & Private not for profit & 0.07 & 0.26 & 0.00 & 0.00 & 0.00 \\
\hline & Private for profit & 0.14 & 0.34 & 0.00 & 0.00 & 1.00 \\
\hline \multirow[t]{4}{*}{ Long stay wards } & Total & 0.61 & 0.49 & 1.00 & 0.00 & 1.00 \\
\hline & Public & 0.85 & 0.36 & 1.00 & 0.00 & 1.00 \\
\hline & Private not for profit & 0.67 & 0.47 & 1.00 & 0.00 & 1.00 \\
\hline & Private for profit & 0.33 & 0.47 & 0.00 & 0.00 & 1.00 \\
\hline \multirow[t]{4}{*}{ Share of Specialised nurses } & Total & 0.06 & 0.15 & 0.00 & 0.00 & 0.14 \\
\hline & Public & 0.05 & 0.10 & 0.00 & 0.00 & 0.13 \\
\hline & Private not for profit & 0.06 & 0.19 & 0.00 & 0.00 & 0.15 \\
\hline & Private for profit & 0.06 & 0.16 & 0.00 & 0.00 & 0.22 \\
\hline
\end{tabular}




\section{Net Pay}

\begin{tabular}{|c|c|c|c|c|c|}
\hline & & Mean & SD & Mean & SD \\
\hline \multirow[t]{3}{*}{ Pay of Nurse Assistants } & Public & 11.33 & 20.47 & 13.32 & 21.11 \\
\hline & $\begin{array}{l}\text { Private not for profit } \\
\text { FEHAP Agreement }\end{array}$ & 10.02 & 18.87 & 13.41 & 19.13 \\
\hline & $\begin{array}{l}\text { Private for profit } \\
\text { FHP Agreement }\end{array}$ & 9.53 & 16.61 & 12.43 & 17.83 \\
\hline \multirow[t]{3}{*}{ Pay of Registered Nurses } & Public & 14.18 & 21.57 & 16.58 & 21.42 \\
\hline & $\begin{array}{l}\text { Private not for profit } \\
\text { FEHAP Agreement }\end{array}$ & 13.71 & 20.65 & 18.38 & 21.08 \\
\hline & $\begin{array}{l}\text { Private for profit } \\
\text { FHP Agreement }\end{array}$ & 13.35 & 21.33 & 17.41 & 22.39 \\
\hline
\end{tabular}


Table 3: Spatial Variation in the Competitiveness of Nurses Pay in France

Nurse assistants

\begin{tabular}{|c|c|c|c|c|c|}
\hline & \multirow{2}{*}{$\begin{array}{l}\text { Non hospital } \\
\text { PUSSWD- } \\
\text { PPCSSWD }\end{array}$} & \multicolumn{2}{|c|}{ Hospital sector } & \multirow{2}{*}{$\begin{array}{l}\text { Non hospital } \\
\text { PUSSWD- } \\
\text { PPCSSWD }\end{array}$} & \multirow{2}{*}{$\begin{array}{c}\text { Hospital sector } \\
\text { PUSSWD- } \\
\text { PNPSSWD }\end{array}$} \\
\hline & & $\begin{array}{l}\text { PUSSWD- } \\
\text { PNPSSWD }\end{array}$ & $\begin{array}{l}\text { PUSSWD- } \\
\text { PPSSWD }\end{array}$ & & \\
\hline Obs & 96 & 85 & 94 & 96 & 85 \\
\hline Missing & 0 & 11 & 2 & 0 & 11 \\
\hline Min & -0.063 & 0.1917 & 0.1947 & -0.033 & -0.1942 \\
\hline Max & 0.093 & 0.4371 & 0.3364 & 0.176 & 0.0124 \\
\hline Range & 0.156 & 0.2454 & 0.1417 & 0.209 & 0.2066 \\
\hline Std. dev. & 0.026 & 0.0408 & 0.0290 & 0.034 & 0.0422 \\
\hline
\end{tabular}

Where PU stands for public hospitals, PPC stands for non hospitals private for profit, PNP stands for hospitals private not for profit and PP stands for hospitals private for profit. The mean of the SSWD gap has been standardised to zero and is not therefore reported. 
Table 4: Adjusted Staffing Levels

\begin{tabular}{lllllll}
\hline \multicolumn{1}{c}{ Variables } & \multicolumn{1}{c}{ Hospitals } & Mean & SD & P50 & P10 & P90 \\
\hline $\begin{array}{l}\text { Nurse Assistants adjusted } \\
\text { staffing levels }\end{array}$ & Total & 35.21 & 37.14 & 21.54 & 5.06 & 89.72 \\
& Public & 66.32 & 42.30 & 54.41 & 21.70 & 125.49 \\
& Private not for profit & 18.63 & 18.08 & 14.67 & 3.08 & 37.32 \\
& Private for profit & 15.17 & 11.06 & 12.61 & 3.79 & 30.39 \\
\hline $\begin{array}{l}\text { Registered nurses adjusted } \\
\text { staffing levels }\end{array}$ & Total & 38.58 & 45.93 & 18.77 & 5.82 & 106.55 \\
& Public & 65.48 & 60.01 & 41.45 & 9.63 & 153.27 \\
& Private not for profit & 23.03 & 28.86 & 11.00 & 3.61 & 63.88 \\
& Private for profit & 22.16 & 17.56 & 17.05 & 6.30 & 46.94 \\
\hline
\end{tabular}


Table 5: Nurse Assistants staff levels models Equation 3, (2825 obs.)

Eq. 3

Test of Fit Chi Square

PUSSWD-PPCSSWD, PUSSWD-PNPSSWD, PUSSWD-PPSSWD, $<0.001^{* * *}<0.001^{* * *} \quad<0.001^{* * *}$

\begin{tabular}{|c|c|c|c|c|c|c|}
\hline & Estimate & Pvalue & Estimate & Pvalue & Estimate & Pvalue \\
\hline Intercept & 37.87 & $<0.001^{* * *}$ & 37.223 & $<0.001^{* * *}$ & 37.385 & $<0.001^{* * *}$ \\
\hline $\begin{array}{l}\text { Nurse Assistants Gap (PUSSWD- } \\
\text { PPCSSWD) }\end{array}$ & 3.43 & $<0.001^{* * *}$ & & & & \\
\hline $\begin{array}{l}\text { Nurse Assistants Gap (PUSSWD- } \\
\text { PNPSSWD) }\end{array}$ & & & -0.2 & 0.823 & & \\
\hline Nurse Assistants Gap (PUSSWD-PPSSWD) & & & & & 1.869 & $0.056^{*}$ \\
\hline Activity MSO & 21.042 & $<0.001^{* * *}$ & 21.436 & $<0.001^{* * *}$ & 21.282 & $<0.001^{* * *}$ \\
\hline Activity PSY & 6.918 & $0.033^{* *}$ & 6.625 & $0.038^{* *}$ & 6.496 & $0.043^{* *}$ \\
\hline Activity LST & 12.761 & $<0.001^{* * *}$ & 13.601 & $<0.001^{* * *}$ & 13.601 & $<0.001^{* * *}$ \\
\hline Share of Nurse Specialists & 40.038 & $<0.001^{* * *}$ & 40.423 & $<0.001^{* * *}$ & 40.812 & $<0.001^{* * *}$ \\
\hline Technology 1 & 2.573 & $<0.001^{* * *}$ & 2.44 & $<0.001^{* * *}$ & 2.376 & $<0.001^{* * *}$ \\
\hline Technology 2 & -0.161 & 0.84 & -0.113 & 0.892 & -0.175 & 0.832 \\
\hline Technology 3 & 2.2 & $0.038^{* *}$ & 2.228 & $0.038^{* *}$ & 2.126 & $0.046^{* *}$ \\
\hline Size 2 & -5.403 & $<0.001^{* * *}$ & -5.193 & $<0.001^{* * *}$ & -5.238 & $<0.001^{* * *}$ \\
\hline Occupancy Rate 1 & 13.347 & $<0.001^{* * *}$ & 13.262 & $<0.001^{* * *}$ & 13.342 & $<0.001^{* * *}$ \\
\hline Occupancy Rate 2 & 10.508 & $<0.001^{* * *}$ & 10.887 & $<0.001^{* * *}$ & 10.879 & $<0.001^{* * *}$ \\
\hline Occupancy Rate 3 & 3.924 & $0.002^{* * *}$ & 3.9 & $0.003^{* * *}$ & 3.876 & $0.003^{* * *}$ \\
\hline
\end{tabular}


Table 6: Registered Nurses staff levels models Equation 3, (2825 obs.)

Eq. 3

PUSSWD-PPCSSWD, PUSSWD-PNPSSWD PUSSWD-PPSSWD,

$<0.001^{* * *}<0.001^{* * *} \quad<0.001^{* * *}$

\begin{tabular}{lcccccc} 
& Estimate & Pvalue & Estimate & Pvalue & Estimate & Pvalue \\
\hline Intercept & 44.554 & $<0.001^{* * *}$ & 43.986 & $<0.001^{* * *}$ & 44.498 & $<0.001^{* * *}$
\end{tabular}

Registered Nurses Gap (PUSSWDPPCSSWD)

$1.014 \quad 0.423$

Registered Nurses Gap (PUSSWDPNPSSWD)

$-1.231 \quad 0.325$

Registered Nurses Gap (PUSSWDPPSSWD)

Activity MSO

5.078

$<0.001^{* * *} \quad 15.614<0.001^{* * *}$

$1 \quad 0.41$

Activity PSY

Activity LST

Share of Nurse Specialists

15.078

$<0.001^{* * *}$

$42.92<0.001^{* * *}$

$15.142<0.001^{* * *}$

42.872

$-3.158$

0.386

$42.871<0.001^{* * *}$

$-3.406$

0.349

71.429

$<0.001^{* * *}$

$-3.404$

0.35

71.675

$<0.001^{* * *}$

4.105

$<0.001^{* * *}$

71.733

$<0.001^{* * *}$

$4.141<0.001^{* * *}$

4.123

$<0.001^{* * *}$

Technology 2

$-0.279$

0.816

$-0.23$

0.848

$-0.324$

0.789

Technology 3

3.279

$0.025^{*}$ *

3.222

$0.028^{* *}$

3.273

$0.026^{* *}$

Size 2

$-2.534$

$0.002^{* * *}$

$-2.517$

$0.002^{* * *}$

$-2.544$

$0.002^{* * *}$

Occupancy Rate 1

21.896

$<0.001^{* *}$

21.811

$<0.001^{* * *}$

$21.888<0.001^{* * *}$

Occupancy Rate 2

16.594

$<0.001^{* *}$

16.682

$<0.001^{* * *}$

16.658

$<0.001^{* * *}$

Occupancy Rate 3

$6.123<0.001^{* * *}$

$6.126<0.001^{* * *}$

6.092

$<0.001^{* *}$ 
Table 7: Nurse Assistants staff levels models. Equation 4 (2825 obs.)

Eq. 4

Test of Fit Chi Square

PUSSWD-PPCSSWD, PUSSWD-PNPSSWD PUSSWD-PPSSWD,

$<0.001^{* * *}<0.001^{* * *} \quad<0.001^{* * *}$

\begin{tabular}{|c|c|c|c|c|c|c|}
\hline & Estimate & Pvalue & Estimate & Pvalue & Estimate & Pvalue \\
\hline Intercept & 37.541 & $<0.001^{* * *}$ & 37.132 & $<0.001^{* * *}$ & 37.398 & $<0.001^{* * *}$ \\
\hline $\begin{array}{l}\text { Nurse assistants Gap (PUSSWD- } \\
\text { PPCSSWD,) }\end{array}$ & 4.596 & $<0.001^{* * *}$ & & & & \\
\hline $\begin{array}{l}\text { Registered nurses Gap (PUSSWD- } \\
\text { PPCSSWD,) }\end{array}$ & -1.775 & 0.192 & & & & \\
\hline
\end{tabular}

Nurse assistants Gap (PUSSWD-

PNPSSWD)

\begin{tabular}{|c|c|c|c|c|c|}
\hline & & 0.085 & 0.936 & & \\
\hline & & -0.67 & 0.592 & & \\
\hline & & & & 1.838 & 0.125 \\
\hline & & & & 0.058 & 0.963 \\
\hline 21.333 & $<0.001^{* * *}$ & 21.576 & $<0.001^{* * *}$ & 21.274 & $<0.001^{* * *}$ \\
\hline 6.961 & $0.031^{* *}$ & 6.662 & $0.037^{* *}$ & 6.5 & $0.042^{* *}$ \\
\hline 12.786 & $<0.001^{* * *}$ & 13.596 & $<0.001^{* * *}$ & 13.591 & $<0.001^{* * *}$ \\
\hline 39.832 & $<0.001^{* * *}$ & 40.289 & $<0.001^{* * *}$ & 40.811 & $<0.001^{* * *}$ \\
\hline 2.579 & $<0.001^{* * *}$ & 2.437 & $<0.001^{* * *}$ & 2.377 & $<0.001^{* * *}$ \\
\hline-0.127 & 0.875 & -0.095 & 0.909 & -0.178 & 0.83 \\
\hline 2.155 & $0.042^{* *}$ & 2.216 & $0.039^{* *}$ & 2.129 & $0.046^{* *}$ \\
\hline-5.418 & $<0.001^{* * *}$ & -5.203 & $<0.001^{* * *}$ & -5.24 & $<0.001^{* * *}$ \\
\hline 13.305 & $<0.001^{* * *}$ & 13.237 & $<0.001^{* * *}$ & 13.342 & $<0.001^{* * *}$ \\
\hline 10.569 & $<0.001^{* * *}$ & 10.873 & $<0.001^{* * *}$ & 10.876 & $<0.001^{* * *}$ \\
\hline 3.912 & $0.002^{* * *}$ & 3.902 & $0.002^{* * *}$ & 3.876 & $0.003^{* * *}$ \\
\hline & $0.03^{*}$ & & 0.37 & & 0.94 \\
\hline
\end{tabular}

Registered nurses Gap (PUSSWDPNPSSWD) 


\section{Equation 5}

\begin{tabular}{|c|c|c|c|c|c|c|}
\hline \multirow[t]{2}{*}{ Test of Fit Chi Square } & \multicolumn{2}{|c|}{$\begin{array}{l}\text { PUSSWD-PPCSSWD } \\
<0.001^{* * *}\end{array}$} & \multicolumn{2}{|c|}{$\begin{array}{l}\text { PUSSWD-PNPSSWD } \\
<0.001^{* * *}\end{array}$} & \multicolumn{2}{|c|}{$\begin{array}{l}\text { PUSSWD-PPSSWD } \\
<0.001^{* * *}\end{array}$} \\
\hline & Estimate & Pvalue & Estimate & Pvalue & Estimate & Pvalue \\
\hline Intercept & 44.513 & $<0.001^{* * *}$ & 44.045 & $<0.001^{* * *}$ & 44.417 & $<0.001^{* * *}$ \\
\hline $\begin{array}{l}\text { Nurse assistants Gap (PUSSWD- } \\
\text { PPCSSWD,) }\end{array}$ & 2.743 & $0.064^{*}$ & & & & \\
\hline $\begin{array}{l}\text { Registered nurses Gap (PUSSWD- } \\
\text { PPCSSWD,) }\end{array}$ & -0.74 & 0.615 & & & & \\
\hline $\begin{array}{l}\text { Nurse assistants Gap (PUSSWD- } \\
\text { PNPSSWD) }\end{array}$ & & & 0.743 & 0.574 & & \\
\hline $\begin{array}{l}\text { Registered nurses Gap (PUSSWD- } \\
\text { PNPSSWD) }\end{array}$ & & & -1.587 & 0.29 & & \\
\hline Nurse assistants Gap (PUSSWD-PPSSWD) & & & & & 0.943 & 0.468 \\
\hline $\begin{array}{l}\text { Registered nurses Gap (PUSSWD- } \\
\text { PPSSWD) }\end{array}$ & & & & & 0.422 & 0.777 \\
\hline Activity MSO & 15.19 & $<0.001^{* * *}$ & 15.645 & $<0.001^{* * *}$ & 15.173 & $<0.001^{* * *}$ \\
\hline Activity PSY & 43.052 & $<0.001^{* * *}$ & 42.926 & $<0.001^{* * *}$ & 42.789 & $<0.001^{* * *}$ \\
\hline Activity LST & -3.756 & 0.299 & -3.258 & 0.373 & -3.289 & 0.367 \\
\hline Share of Nurse Specialists & 71.301 & $<0.001^{* * *}$ & 71.305 & $<0.001^{* * *}$ & 71.878 & $<0.001^{* * *}$ \\
\hline Technology 1 & 4.207 & $<0.001^{* * *}$ & 4.116 & $<0.001^{* * *}$ & 4.087 & $<0.001^{* * *}$ \\
\hline Technology 2 & -0.27 & 0.822 & -0.205 & 0.865 & -0.314 & 0.795 \\
\hline Technology 3 & 3.218 & $0.028^{* *}$ & 3.232 & $0.028^{* *}$ & 3.211 & $0.029^{* *}$ \\
\hline Size 2 & -2.646 & $0.002^{* * *}$ & -2.526 & $0.002^{* * *}$ & -2.542 & $0.002^{* * *}$ \\
\hline Occupancy Rate 1 & 21.894 & $<0.001^{* * *}$ & 21.796 & $<0.001^{* * *}$ & 21.91 & $<0.001^{* * *}$ \\
\hline Occupancy Rate 2 & 16.479 & $<0.001^{* * *}$ & 16.669 & $<0.001^{* * *}$ & 16.68 & $<0.001^{* * *}$ \\
\hline Occupancy Rate 3 & 6.125 & $<0.001^{* * *}$ & 6.116 & $<0.001^{* * *}$ & 6.093 & $<0.001^{* * *}$ \\
\hline Eq. 4 vs. Eq. 3, chi square: & & $0.006^{* * *}$ & & 0.38 & & 0.27 \\
\hline
\end{tabular}


Appendix Table A: Descriptive Statistics for the components derived by Principal Component Analysis

\begin{tabular}{|c|c|c|c|c|c|c|}
\hline Variables & Hospitals & Mean & SD & P50 & P10 & P90 \\
\hline \multirow[t]{4}{*}{ Nurse Assistants } & Total & 88.10 & 448.87 & 30.50 & 6.00 & 171.48 \\
\hline & Public & 190.58 & 721.53 & 79.40 & 27.40 & 379.05 \\
\hline & Private not for profit & 28.47 & 38.61 & 18.00 & 3.65 & 64.21 \\
\hline & Private for profit & 25.79 & 26.46 & 16.80 & 4.30 & 58.28 \\
\hline \multirow[t]{4}{*}{ Registered nurses } & Total & 110.86 & 473.44 & 24.08 & 6.50 & 255.74 \\
\hline & Public & 230.81 & 756.07 & 59.70 & 10.25 & 523.16 \\
\hline & Private not for profit & 39.73 & 68.27 & 13.17 & 4.00 & 110.10 \\
\hline & Private for profit & 38.90 & 43.51 & 22.87 & 7.00 & 97.77 \\
\hline \multirow[t]{4}{*}{ Staff-mix } & Total & 0.51 & 0.17 & 0.52 & 0.26 & 0.73 \\
\hline & Public & 0.43 & 0.17 & 0.42 & 0.23 & 0.65 \\
\hline & Private not for profit & 0.50 & 0.18 & 0.48 & 0.28 & 0.75 \\
\hline & Private for profit & 0.59 & 0.13 & 0.59 & 0.42 & 0.75 \\
\hline \multirow[t]{4}{*}{ Change in staff-mix } & Total & 0.005 & 0.11 & 0.00 & -0.07 & 0.08 \\
\hline & Public & 0.004 & 0.09 & 0.00 & -0.07 & 0.08 \\
\hline & Private not for profit & 0.008 & 0.14 & 0.00 & -0.09 & 0.10 \\
\hline & Private for profit & 0.005 & 0.10 & 0.00 & -0.07 & 0.08 \\
\hline \multirow[t]{4}{*}{$\begin{array}{l}\text { Medicine, Surgery and } \\
\text { Obstetric }\end{array}$} & Total & 0.54 & 0.50 & 1.00 & 0.00 & 1.00 \\
\hline & Public & 0.72 & 0.45 & 1.00 & 0.00 & 1.00 \\
\hline & Private not for profit & 0.29 & 0.45 & 0.00 & 0.00 & 1.00 \\
\hline & Private for profit & 0.54 & 0.50 & 1.00 & 0.00 & 1.00 \\
\hline \multirow[t]{4}{*}{ Psychiatric wards } & Total & 0.15 & 0.36 & 0.00 & 0.00 & 1.00 \\
\hline & Public & 0.22 & 0.41 & 0.00 & 0.00 & 1.00 \\
\hline & Private not for profit & 0.07 & 0.26 & 0.00 & 0.00 & 0.00 \\
\hline & Private for profit & 0.14 & 0.34 & 0.00 & 0.00 & 1.00 \\
\hline \multirow[t]{4}{*}{ Long stay wards } & Total & 0.61 & 0.49 & 1.00 & 0.00 & 1.00 \\
\hline & Public & 0.85 & 0.36 & 1.00 & 0.00 & 1.00 \\
\hline & Private not for profit & 0.67 & 0.47 & 1.00 & 0.00 & 1.00 \\
\hline & Private for profit & 0.33 & 0.47 & 0.00 & 0.00 & 1.00 \\
\hline \multirow[t]{4}{*}{ Share of Specialised nurses } & Total & 0.06 & 0.15 & 0.00 & 0.00 & 0.14 \\
\hline & Public & 0.05 & 0.10 & 0.00 & 0.00 & 0.13 \\
\hline & Private not for profit & 0.06 & 0.19 & 0.00 & 0.00 & 0.15 \\
\hline & Private for profit & 0.06 & 0.16 & 0.00 & 0.00 & 0.22 \\
\hline
\end{tabular}

